\title{
High energy-consuming industrial coordinating symbiosis pattern performance evaluation of the Beijing-Tianjin-Hebei development
}

\author{
$\mathrm{Li} \mathrm{Li}^{\dagger}$ \\ School of Economics and Management, \\ Beijing Information Science \& Technology University \\ Beijing, 100085, China \\ E-mail: lilinw2001@126.com \\ www.bistu.edu.cn \\ Yue $\mathrm{Gu}$ \\ School of Economics and Management, \\ Beijing Information Science \& Technology University \\ Beijing, 100085, China \\ E-mail:791289960@qq.com \\ Jian-Jun Wang \\ School of Economics and Management, \\ North China Electric Power University \\ Beijing, 102206, China \\ E-mail:wangjianjunhd@126.com
}

\begin{abstract}
The excessive consumption of fossil fuels brings air pollution problem in Beijing, and integration of Beijing-Tianjin-Hebei will join a new coordinating development for future development, it will form a symbiosis pattern. How to choose the symbiosis pattern is a key issue of the development. This paper built an index system from three aspects including 13 indicators, and used AHP to determine the weight of the indexes. By the case study, the result shows that the future development of the Beijing-Tianjin-Hebei development should be chosen as the integration symbiosis pattern..
\end{abstract}

Keywords: High Energy-Consuming Industrial; Symbiosis Pattern; Beijing-Tianjin-Hebei; Region Development.

\footnotetext{
${ }^{*}$ The authors gratefully acknowledge the financial support through Beijing Philosophy and Social Science Fund Project (13JGC074, 14JGC108), School Research Funding Project of Beijing Information Science and Technology University (1335011) and National Natural Science Foundation of China (71373030).
} 


\section{Introduction}

With the rapid economic development of China, the energy consumption is also increasing fast, however, the excessive consumption of fossil fuels also brings more pollutants, especially in big cities like Beijing, Shanghai, the haze becomes a hot focuses of public attention in recent years. In order to maintain the sustainable development of Beijing to ease the pressure of air pollution, Beijing, Tianjin, Hebei coordinated development of regional integration issues are raised. The integration of Beijing-Tianjin-Hebei will join a new situation development of a new model for future development in the three places.

The second industry uses larger energy consumptions in all the industries, and energy-intensive industries is also the largest one in the second industry. According to Beijing-Tianjin-Hebei next five years Development Plan system, the core of the future development pattern is to ease the integration of ordered non-capital function, and prominent the location of Beijing political and cultural center, international exchange center and the center of technological innovation, Tianjin undertakes high-end equipment, electronic information and other advanced manufacturing industries, and develops into port transport advantages of the port city, in the end, the high energy-consuming industries are going to transfer in Hebei. In the future integration of Beijing-Tianjin-Hebei collaborative development model, industrial layout and planning have a clear position division, and the pattern of high energy-intensive industries within the Beijing-Tianjin-Hebei region will be a pattern of industrial symbiosis.

Some scholars study the high energy-intensive industries development from the perspective of sustainable development of energy-intensive industries production efficiency and the environmental impact evaluation [1-2]. Some study the performance from the recycling economy perspective to evaluate the performance of energy-intensive industry [3-5].These studies have achieved good results, but it is regret that there are few studies on high energy-intensive industrial symbiosis model.

This paper studies the integration coordinated development of high energyintensive industrial symbiosis of Beijing-Tianjin-Hebei region, and from the industrial symbiosis perspective, the region's development evaluation is also studied, at last, some suggestions will be given, and provide some references to the region development.

\section{Development Pattern of Industrial Coordinate Symbiosis Analysis}

The symbiosis concept is first proposed by the German biologist Ender bury, and the symbiosis is some different organisms living together. With the development of various disciplines and mutual penetration, symbiosis is no 
longer just for biology. Currently, the symbiosis concept has been extended to the ecological social and economic fields, and have achieved fruitful results. Symbiosis theory thinks that industrial symbiosis is a complete system, which means an intra-industry economic organization as an independent company directly or indirectly, and this improvement brings not only increase enterprise efficiency, but also promote the development of the industry. Therefore, symbiosis can be considered as the basis and foundation of industrial development.

In the symbiosis concept, symbiosis pattern is the key, symbiosis unit is the basis, symbiosis environment is the important external condition. From the organization perspective, the symbiosis pattern is divided into Accidentally symbiosis pattern, occasional symbiosis pattern, continuous symbiosis pattern and integration symbiosis pattern, and the comparison of the four patterns is in Table 1.

Table 1 . The comparison of the four symbiosis patterns

\begin{tabular}{cccc}
\hline Accidentally & $\begin{array}{c}\text { Occasional symbiosis } \\
\text { pattern(O) }\end{array}$ & $\begin{array}{c}\text { Continuous symbiosis } \\
\text { pattern(C) }\end{array}$ & $\begin{array}{c}\text { Integration } \\
\text { symbiosis pattern(I) }\end{array}$ \\
\hline Interaction of a & several interactions of & continuous interactions & form a symbiosis \\
of symbiotic unit in a & organization \\
certain time & Tymbiotic unit between & time & certain time \\
symbiosis unit's & symbiosis unit's & symbiosis unit's & symbiosis unit's \\
interaction in a & interaction in a certain & interaction in many & interaction in all \\
certain aspect & or several aspect & aspect & orient \\
having instability & having instability and & relatively stable & stableand \\
and randomness & randomness & inevitability \\
\hline
\end{tabular}

\section{High Energy-Consuming Industries Symbiosis Pattern Evaluation}

\subsection{The index system construction}

High energy-consuming industries, also known as high energy consumption, high pollution and resource-intensive industries, are including oil processing, coking, processing of nuclear fuel (PPCPNF), production of chemical raw materials and chemical products (MRCMCP), manufacture of non-metallic minerals (MNMP), ferrous metal smelting and rolling processing industry (SPFM), non-ferrous metal smelting and rolling processing industry (SPNM), production and supply of electricity and thermal energy (PSEPHP), which are proposed in the "2010 China national Economic and Social development statistics bulletin".

For evaluating energy-intensive industries symbiosis' pattern collaborative development performance, this paper creates an index system in accordance with the principles of Analytic Hierarchy Process, the system is divided into target layer, criteria layer and indexes, where the target is a high energy-consuming 
industries symbiosis Coordinating development pattern performance, and the details are in Table 2.

Table 2. High energy-consuming industrial symbiosis Coordinating Development Model Performance Evaluation index system

\begin{tabular}{|c|c|c|}
\hline Object lever & Criterion level & indexes \\
\hline \multirow{13}{*}{$\begin{array}{c}\text { High energy- } \\
\text { consuming industrial } \\
\text { symbiosis } \\
\text { Coordinating } \\
\text { Development Model } \\
\text { Performance } \\
\text { Evaluation }\end{array}$} & \multirow{4}{*}{$\begin{array}{l}\text { Economic influence } \\
\text { (B1) }\end{array}$} & GDP contribution rate $(\mathrm{C} 11)$ \\
\hline & & Cost margins(C12) \\
\hline & & Annual growth rate of $\mathrm{GDP}(\mathrm{C} 13)$ \\
\hline & & Fixed assets share of GDP(C14) \\
\hline & \multirow{6}{*}{$\begin{array}{c}\text { Environmental influence } \\
\text { (B2) }\end{array}$} & $\mathrm{CO} 2$ emissions $(\mathrm{C} 21)$ \\
\hline & & NOx emissions $(\mathrm{C} 22)$ \\
\hline & & $\mathrm{SO} 2$ emissions $(\mathrm{C} 23)$ \\
\hline & & $\begin{array}{c}\text { energy intensity of } \\
\text { High energy-consuming industries(C24) }\end{array}$ \\
\hline & & Wastewater emissions $(\mathrm{C} 25)$ \\
\hline & & Solid waste emissions(C26) \\
\hline & \multirow{3}{*}{$\begin{array}{l}\text { Society influence } \\
\text { (B3) }\end{array}$} & Environmental inputs(C31) \\
\hline & & High energy-consuming industry employment(C32) \\
\hline & & Conversion rate of scientific and technological(C33) \\
\hline
\end{tabular}

\subsection{AHP method}

Analytic hierarchy process (AHP) put forward a kind of effectively dealing with the complicated and ambiguous relationship between how to translate into quantitative analysis method. Using the AHP method of level analysis method to determine the index weight steps are as follows:

First of all, the discriminant compared matrix $U$ should be built, in the matrix, $U_{i j}$ is the importance of the relative to the proportion of the 1-9 scale.

Then, calculate the weight of each index. The steps are as follows:

Calculate the product of the judgment matrix each line factors

$$
M_{i}=\prod_{j=1}^{n} x_{i j}, i=1,2, \cdots n
$$

Calculation of the root and Normalization

$$
W_{i}=W_{i} / \sum_{j=1}^{n} W_{j}
$$

Then, the vector $\mathrm{W}$ changes to be the weights. However, it is impossible to ensure the absolute consistency when the elements are comparing with each other. Thus, to keep the reliability of Analytic Hierarchy Process, the consistency of the judgments must be checked after normalizing. And the checking steps are as follows: 
Calculate consistency ratio $\mathrm{CR}$

$$
C R=C I / R I
$$

In the formulas, $R I$ is an average random consistency index, which can be queried in the $R I$ index table. The consistency of the judgment matrix can be accepted when $C R<0.1$.

Finally, Define a candidate set $X$, and give an evaluation score matrix $R$ by experts. Combined with the weights calculated in the above step, the final comprehensive evaluation result can be gotten.

\subsection{Case study}

According to the above evaluation method, through expert survey calculation to obtain the final judgment matrix and the index values, the evaluation results of are as follows:

Table 3. Evaluation result of the four patterns.

\begin{tabular}{cccccc}
\hline indicators & weights & $\mathrm{A}$ & $\mathrm{O}$ & $\mathrm{C}$ & $\mathrm{I}$ \\
\hline Network topology enhancement (C11) & 0.08 & 76 & 80 & 82 & 87 \\
Intermittent energy integration performance (C12) & 0.08 & 76 & 78 & 81 & 83 \\
Power system steady state performance (C13) & 0.08 & 76 & 80 & 83 & 86 \\
Early warning capability (C14) & 0.08 & 73 & 78 & 82 & 87 \\
Automatic distribution capacity (C21) & 0.07 & 64 & 66 & 68 & 71 \\
Demand side interaction capacity (C22) & 0.06 & 65 & 67 & 69 & 70 \\
Real-time data monitoring capacity (C23) & 0.07 & 75 & 76 & 78 & 80 \\
Plug and play capability (C24) & 0.09 & 72 & 77 & 81 & 85 \\
Fault healing power (C25) & 0.12 & 78 & 79 & 80 & 83 \\
Distribution network decision-making (C31) & 0.11 & 76 & 80 & 82 & 84 \\
Accurate load forecasting ability (C32) & 0.08 & 66 & 68 & 71 & 73 \\
Electricity requirement trend analysis (C33) & 0.04 & 74 & 78 & 83 & 84 \\
Automatic control ability (C34) & 0.04 & 62 & 63 & 67 & 69 \\
Distributed computing (C35) & 0.08 & 68 & 73 & 78 & 82 \\
Sum & 1 & 78.07 & 81.37 & 84.43 & 87.58 \\
\hline
\end{tabular}

As the calculation results, the fourth pattern I, which is the integration symbiosis pattern, is suit for Beijing-Tianjin-Hebei development. From the indicators value with the expert judgment, it can be seen that the integration symbiosis pattern's value are all larger than other three patterns. So the integration symbiosis pattern is the most suitable pattern for the Integration of Beijing-Tianjin-Hebei. From the weights, the influence has the larger weights, so in the future, Beijing-Tianjin-Hebei will take more attention to the environment influence of the development. 


\section{Conclusion}

In this paper, the performances evaluation of the symbiosis pattern of BeijingTianjin-Hebei high energy-intensive industries development are studied. The evaluation index system is built from three aspects including 13 indicators, and used AHP to determine the weight of the indexes. By the case study, the result shows that the future development should be chosen as the integration symbiosis pattern.

\section{References}

1. Gong Jian jian, Shen Ke ting. Regional Distribution and Environment Pollution of Energy-intensive Industries in China, The Journal of Quantitative \& Technical Economics, 2, 20-36 (2011).

2. Shen Ke-ting, Gong Jian-jian. Environmental Pollution, Technical Progress, and Productivity Growth of Energy-intensive Industries in China--Empirical Study Based on ETFP, China Industrial Economics, 12, 25-34,(2011).

3. Zheng Ji-liang, Research on Multi-performance Coordination and Change in Circular Economy Process of Energy-intensive Industries [J].Chinese Journal of Management Science, S1, 843-849, (2014).

4. Zheng Ji-liang, Chen Chun-yan, Wang juan, Wu Tong, Multi Performance Coordinated Effect Regulation on Circular Economic Development of Energy-intensive Industries. Chinese Journal of Management Science,S1, 794-800, (2015).

5. Li Li, Jian jun Wang, Zhong fu Tan, Xin quan Ge, Jian Zhang, Xiao zhe Yun. Policies for eliminating low-efficiency production capacities and improving energy efficiency of energy-intensive industries in China [J].Renewable and Sustainable Energy Reviews, 2014, 39: 312-326 